University of Arkansas, Fayetteville

ScholarWorks@UARK

Education Reform Faculty and Graduate

Students Publications

Education Reform

2-3-2017

\title{
More Graduates, Less Criminals? The Economic Impacts of the Milwaukee Parental Choice Program
}

Will Flanders

Wisconsin Institute for Law \& Liberty

Corey A. DeAngelis

University of Arkansas, Fayetteville

Follow this and additional works at: https://scholarworks.uark.edu/edrepub

Part of the Educational Assessment, Evaluation, and Research Commons, Educational Leadership Commons, and the Other Educational Administration and Supervision Commons

\section{Citation}

Flanders, W., \& DeAngelis, C. A. (2017). More Graduates, Less Criminals? The Economic Impacts of the Milwaukee Parental Choice Program. Education Reform Faculty and Graduate Students Publications. Retrieved from https://scholarworks.uark.edu/edrepub/15

This Article is brought to you for free and open access by the Education Reform at ScholarWorks@UARK. It has been accepted for inclusion in Education Reform Faculty and Graduate Students Publications by an authorized administrator of ScholarWorks@UARK. For more information, please contact scholar@uark.edu. 


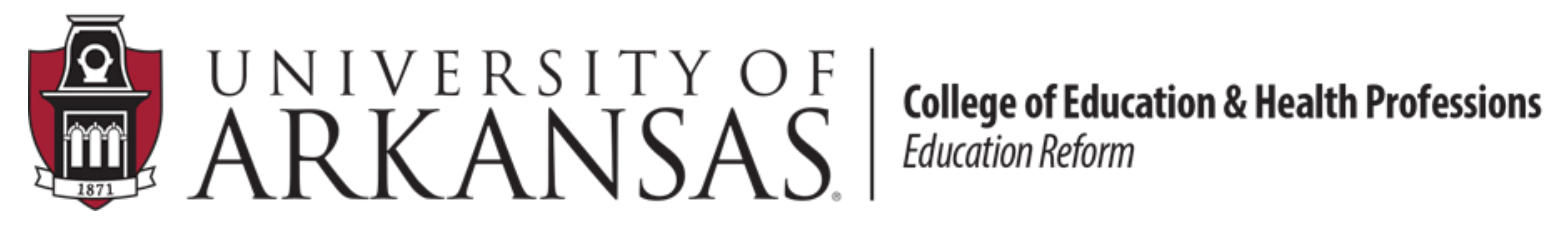

\section{WORKING PAPER SERIES}

\section{More Graduates, Less Criminals? The Economic Impacts of the Milwaukee Parental Choice Program}

Will Flanders, Ph.D.

Corey A. DeAngelis

February 3, 2017

EDRE Working Paper 2017-05

The University of Arkansas, Department of Education Reform (EDRE) working paper series is intended to widely disseminate and make easily accessible the results of EDRE faculty and students' latest findings. The Working Papers in this series have not undergone peer review or been edited by the University of Arkansas. The working papers are widely available, to encourage discussion and input from the research community before publication in a formal, peer reviewed journal. Unless otherwise indicated, working papers can be cited without permission of the author so long as the source is clearly referred to as an EDRE working paper. 


\title{
MORE GRADUATES, LESS CRIMINALS? THE ECONOMIC IMPACTS OF THE MILWAUKEE PARENTAL CHOICE PROGRAM
}

\author{
Will Flanders, Ph.D. \\ Education Research Director, \\ Wisconsin Institute for Law \& Liberty \\ flanders@will-law.org \\ Corey A. DeAngelis \\ Department of Education Reform, \\ University of Arkansas \\ cadeange@uark.edu
}

February 3, 2017

\section{Acknowledgements}

The content of the report is solely the responsibility of the authors and does not necessarily represent the views of the University of Arkansas. Corresponding author is Corey A. DeAngelis, cadeange@email.uark.edu. 


\begin{abstract}
Although an abundance of research indicates that private schooling can benefit individual children through higher test scores, the effects on society are less clear.

We monetize and forecast the social impacts of the Milwaukee Parental Choice Program (MPCP) in the United States. We use existing literature on the impacts of the MPCP on criminal activity and graduation rates. Between 2016 and 2035, students who use a voucher in the MPCP will generate additional economic benefits of $\$ 473$ million associated with higher graduation rates, and \$26 million associated with fewer felonies and misdemeanors, relative to their traditional public school peers.
\end{abstract}

Keywords: school choice; school vouchers; economic impact; civic education 


\section{Introduction}

St. Marcus Lutheran School, a high-performing school in Milwaukee, decided to consider adding another campus in 2014. St. Marcus, a private school in the Milwaukee Parental Choice Program (MPCP), demonstrates high school graduation rates averaging around 90\%, even though more than $90 \%$ of its students are from low-income families. For their expansion, St. Marcus inquired to the City of Milwaukee about purchasing former Lee Elementary School, an empty Milwaukee Public School (MPS) building. Because it can hold up to 600 children, Lee was an ideal facility for St. Marcus.

St. Marcus offered to purchase Lee from the City for its appraised value of $\$ 880,000$. However, the City of Milwaukee wanted St. Marcus to pay an additional \$1.3 million to cover the cost to Milwaukee taxpayers for the expansion of St. Marcus and the voucher program. Critics of the school choice program have long cited the funding flaw, which allows Milwaukee to raise property taxes to cover the lost revenue for students leaving MPS for the MPCP. Unfortunately, because the City made the fiscal effects of the program a condition of the transaction, St. Marcus was unable to pay the artificially-high price.

The fiscal impact of the MPCP has long been a source of contention with the City, MPS Board, and the state of Wisconsin. However, the debate usually focuses on one piece of a complex puzzle. It neglects any discussion of the economic benefit of school choice. For example, students who graduate from St. Marcus are more likely to land a job, stay out of our corrections systems, and become upstanding members of the community. All of this has a sizable economic impact for the child, city, and state.

This study - the first of its kind in Milwaukee - attempts to monetize the economic impact of the Milwaukee Parental Choice Program over a 20-year period. To perform this 
analysis, we use two academic studies of the program. DeAngelis and Wolf (2016) find that students in the MPCP are 5 percentage points less likely to be convicted of misdemeanors and 3 percentage points less likely to be convicted of felonies than their matched MPS peers. Cowen et al. (2013) find that students in the MPCP are 4\% more likely to graduate from high school than their MPS counterparts. We also utilize studies (Aos et al., 2001; Levin 2009; McCollister et. al. 2010) that monetized the economic benefit of students graduating from high school and not committing crimes. As a result, we are able to estimate the economic benefit of higher graduation rates and lower crime rates of students in the voucher program.

\section{Existing Research}

\section{Cost Savings of the MPCP}

The Milwaukee Parental Choice Program is a state-funded program that gives families with incomes up to $300 \%$ of the federal poverty level a voucher to attend a private school of their choice. Since the MPCP started in 1990, it is the longest-standing voucher program in the United States. In 2016, nearly 28,000 children in Milwaukee use the program to attend a private school.

Most examinations have found that the program has represented a cost saving to the state of Wisconsin. Because it costs the state about $\$ 2,000$ more to send a child to MPS rather than a private school, Robert Costrell (2012) estimated that this funding disparity saved the state approximately $\$ 46.7$ million in fiscal year 2011. Spalding (2014) estimated that the MPCP has saved the state $\$ 238$ billion since implementation.

The funding flaw has prevented Milwaukee taxpayers from sharing the financial benefits of the MPCP. It resulted from MPS being unable to count students that attend a private school in the MPCP for their total enrollment. Despite not being able to count the students, the state aid 
received by MPS was still reduced by a percentage for students who entered the MPCP. Milwaukee has been allowed to increase taxes to make up this difference and maintain current levels of per-pupil revenue. The result of this has been that the benefits of choice accrue to Wisconsin state taxpayers and not only those in Milwaukee. Nonetheless, the aggregate result statewide remains positive (Costrell, 2012). Furthermore, the funding flaw is being gradually phased out, and within ten years, the MPCP is no longer expected to represent an additional cost to Milwaukee property tax payers.

While these areas of savings have been well studied, measurement of the economic benefits of school choice remain largely unexamined. However, Wolf and McShane (2013) estimated the economic benefits of the voucher program in Washington D.C. They found that D.C. Opportunity Scholarship Program (OSP) generated more than $\$ 164$ million in benefits during its first five years of operation, and calculated a benefit-cost ratio of 2.62. David Deming (2011) examined the economic benefits of school choice in the Charlotte-Mecklenburg school district with respect to crime. He found experimental evidence, since admission was decided by lotteries, to suggest that charter schools significantly reduced crime. He also found that the total societal cost for lottery winners is approximately $\$ 5,400$ less than for those who fail to win admission to the choice program. We conduct a similar analysis using the MPCP.

\section{Criminality and School Choice}

In Milwaukee, the fear that children will become embroiled in the criminal justice system represents a constant threat in the minds of poor and minority parents. In Wisconsin, 1 in 8 African American men are behind bars in state and local prisons (Pawasarat and Quinn, 2013). Beyond the obvious psychological impacts, high incarceration rates have deleterious effects on 
the potential income and tax revenue generated by the convicted criminals, as well as on the lives of the victims of crimes.

There is growing evidence that school choice programs represent a safer alternative for students due to decreased likelihood of involvement in the criminal justice system. Dills and Hernandez-Julian (2011) used a nationally-representative sample of high school students to show that teens from areas with larger amounts of school choice report lower levels of involvement in criminal activity. Dobbie and Fryer (2015) found experimental evidence that the school voucher program in New York City eliminated incarceration for males and largely reduced teen pregnancy for females. In Milwaukee, DeAngelis and Wolf (2016) found that students who use a voucher in the Milwaukee Parental Choice Program for four or more years are less likely to be accused and convicted of misdemeanors and felonies. Their Milwaukee-specific estimates are the basis for the subsequent analyses in this paper.

\section{Graduation and School Choice}

Because graduation rates are a common metric of a high quality school, there has been a significant amount of research dedicated to how it relates to participation in voucher programs. Taking advantage of a lottery system that effectively randomized whether students would be offered a voucher, Wolf et al. (2013) found experimental evidence to suggest that the offer of a school voucher in D.C. raised the likelihood that a given student would graduate high school by 12 percentage points.

Cowen et al. (2013) utilized sophisticated matching methods identical to those used by DeAngelis and Wolf to create a cohort of students in MPS that were similar across a number of dimensions including demographics, neighborhood, and prior educational attainment to students in the MPCP. These authors estimate that participation in the voucher program increases 
graduation by approximately 4 percent. Other research on Milwaukee by Warren (2011) found that graduation rates in the MPCP are as much as 12 percent higher than the public school system. We rely on the more conservative findings of Cowen et al. (2013) in our subsequent analyses.

\section{Methods and Data}

For the purpose of this paper, we define economic benefit (or cost) as any financial gain (or loss) realized at any level of society - whether individual or governmental - as a result of graduating from high school or avoiding the conviction of a crime. For example, the most obvious economic benefits accrue to the individual. If someone graduates from high school, studies show that he is more likely to earn a significantly higher income in his life, less likely to become involved in the criminal justice system, and less likely to incur health problems. There are benefits for government too. Individuals who earn higher incomes pay more in state and federal income taxes. Those who avoid committing crimes do not force society to bear the cost of their incarceration as well as the need for additional police officers. Healthier individuals are less likely to need expensive medical care and less likely to need society to pay for it.

We quantify all of these benefits. Economists and education researchers have produced a number of peer-reviewed estimates of the costs and benefits that society realizes when an individual does or does not engage in a particular activity.

\section{Graduation Impact}

Studies of the economic benefits of high school graduation are particularly prolific. Levin (2009) estimated the economic benefits of graduation in a number of categories, including the difference in tax revenue generated, public health expenditures, and welfare savings. Levin estimated tax revenue generated through analysis of income data on the Current Population 
Survey. These data are run through the TAXSIM program, which estimates the taxable income of an individual. The resulting tax levies are averaged across individuals with differing levels of educational attainment, including those who graduate high school. To estimate healthcare cost savings, Levin utilizes data from the 2006 Medical Expenditure Survey from the U.S.

Department of Health. This survey included questions on enrollment in Medicare and Medicaid coverage, which Levin broke down by educational attainment through logistic regression.

To estimate the saving associated with lower utilization of welfare programs, Levin borrows from the research of Waldfogel, Garfinkel and Kelly (2007) who estimate the effect of educational attainment on receipt of TANF, food stamps, and housing vouchers. The estimates of Waldfogel and colleagues are combined with data on the average monthly amount of each welfare benefit. When these components are aggregated, Levin estimates the savings at $\$ 209,100$ over the lifetime of the hypothetical graduate. Because there is likely to be a correlation between high school graduation and criminal behavior, we do not include the portion of Levin's estimates that are the results of reduced criminality. Consequently, we use an estimate of $\$ 182,500$ for the benefit of graduation.

\section{Crime Reduction Impact}

For the societal cost of crime, we rely on the recent estimates produced by McCollister, French, and Fang (2010) for felonies and Aos et al. (2001) for misdemeanors. McCollister French, and Fang (2010) collected data from a wide variety of sources to estimate the societal cost of crime. To estimate the cost of crime prevention and the cost of crime prosecution, the authors gathered data from the 2005 "Justice Expenditure and Employment" report by the Bureau of Justice Statistics. To estimate the mortality cost of crime victimization, data were gathered from the CPS on lifetime earnings and employment. To estimate the cost of other 
crimes, the work of Cohen (1988) that provides estimates of jury compensation for various crimes was updated to 2010 levels. The cost to an individual from conviction for criminal behavior was conservatively estimated using data on the federal minimum wage times the total number of productivity hours lost for each crime committed. They combine these data to arrive at the average cost to society of a number of categories of crime. Misdemeanor arrests are significantly less costly to society. When compared to felonies, they generally carry neither the lengthy prison sentences, social stigma, or effect on lifetime earnings. Consequently, Aos et al.'s estimates of the cost for a misdemeanor only include the estimated cost of police work and court administration.

We found the specific crimes committed by former students in the Milwaukee dataset and matched them with the costs of crimes observed in the source data sets. These costs are then averaged across crime types to arrive at the average cost of each. Rape and murder are left out of these averages because their costs are tremendously high and could distort the findings. Because of this, our estimates could be considered conservative. The societal cost of a misdemeanor is estimated at $\$ 1,782$ and the average cost of a felony at $\$ 34,832$, in 2016 dollars.

\section{Data Used}

This paper builds upon existing work by DeAngelis and Wolf (2016) that estimated the effect of the MPCP on the extent to which students were involved in criminal activity. DeAngelis and Wolf utilized a sophisticated matching method to create a comparable sample of students in the MPCP and MPS. They matched students that lived in the same neighborhood at baseline, which allowed their study to better account for unobservable characteristics (such as motivation level) that are also involved in the selection of residence. Other factors used in the 
baseline match included grade, race, gender, English-language learner status, and math and reading test scores.

Selection bias is a legitimate concern raised by critics of school choice studies because participants can choose to use a program due to unobservable factors (such as parental involvement) that could also be related to the outcome of interest. However, the baseline matching method used by DeAngelis and Wolf is the best approximation of a randomized experiment when such an experiment is unrealistic to conduct (Stuart and Rubin, 2007; Bifulco, 2012).

\section{Calculations}

DeAngelis and Wolf (2016) found that MPCP attendance reduced conviction for misdemeanors by approximately 5 percentage points, and reduced conviction for felonies by approximately 3 percentage points. We combine these estimates with Levin (2009) study on the economic benefit of graduation.

For the calculation of our analysis of the economic benefits of graduation, we similarly combine existing research on the impact of MPCP on graduation rates with research on the economic benefits of graduating high school. Cowen and co-authors estimate the positive effect of attending an MPCP school on graduation as approximately $4 \%$.

In each case, let $R$ equal the percentage change in the outcome of interest (crime or graduation) for time period i, $N$ equal the total number of students that have gotten at least a four year dose and exited the program by the time period, and $C$ is a constant equal the societal cost of the crime or dropout in 2016 dollars. The estimate for the economic benefit of the program is: 
The estimated economic benefit can be interpreted as the net change in economic benefit by students attending choice schools rather than MPS. We produce three estimates in our analyses: the economic benefit of misdemeanor reductions, felony reductions, and graduation increases.

Our projections on criminality only account for the current 12 th grade students that received at least four years of the program. DeAngelis and Wolf (2016) found that 44 percent of their sample received at least four years of the MPCP, so we assume that the effects are only relevant for that proportion of students in the program. In other words, we take the highly conservative approach of assuming that the 56 percent of students that were in the program for less than four years were not impacted at all. Additionally, since DeAngelis and Wolf searched criminal records when the students were at least 22 years old, we assume that no benefits will accrue until the students reach that age. Since these current students will not reach the age 22 for four more years, our first estimate is for the year 2020. The following estimates assume that enrollment will continue to expand at a similar rate as previous years. The graduation data of Cowen et. al. (2013) do not require these assumptions, leading to a larger poll of potential impact in that part of the study. In our projects, we assume that the MPCP will continue to expand at the same rate it has in the past five years in the subsequent decades. The results should be interpreted as relative to the control group in the original study upon which the projections are based. In both cases, results are relative to a sample of students not in the choice program matched along lines of academic performance, income, and neighborhood.

Since graduating from high school may affect the likelihood of going to prison (Anderson 2014), aggregating the economic benefits from both analyses could inflate our findings. 
Consequently, we consider the economic benefits of graduation and avoiding criminality separately in the results section.

\section{Results}

\section{Crime Reduction}

We combine the results of DeAngelis and Wolf (2016) with the estimates of the economic benefits of reduced criminality from McCollister, French, and Fang (2010) and Aos et al. (2001). Table 2 shows the economic benefit of students that reached 22 years of age and received four years of exposure to the program from 2020 to 2035 .

The first row of Table 1 represents the total number of students who persisted in the MPCP and have reached 22 years old. For example, about 10,304 students received at least four years of the Milwaukee Parental Choice Program and reached the age of 22 between the fall of 2016 and 2025. The second row of the table represents the projected reduction in the number of misdemeanors committed relative to what would have happened if those students had remained in traditional public schools. Between now and 2020, we project a reduction of 55 in the number of misdemeanors committed. Multiplying this number by the estimated societal cost of a misdemeanor yields a net reduced societal cost of approximately $\$ 79,000$ from if the students had remained in public schools. Assuming current enrollment growth continues, we estimate that the MPCP represents a cumulative net economic benefit of $\$ 1.7$ million by 2035 through misdemeanor reduction. 
Table 1: Projected Cumulative Economic Benefits of Decreased Misdemeanors

\begin{tabular}{|l|cccc|}
\hline & $2016-2020$ & $2016-2025$ & $2016-2030$ & $2016-2035$ \\
\hline Total Full Dose Students & 934 & 10,304 & 16,522 & 28,537 \\
Reduction in Misdemeanors & 55 & 246 & 559 & 960 \\
Economic Benefits (Millions) & $\$ 0.08$ & $\$ 0.44$ & $\$ 1.00$ & $\$ 1.71$ \\
\hline
\end{tabular}

Note: Numbers represent the mean estimated economic benefit of the MPCP from reduction in misdemeanors from 2016 to 2035.

These figures are displayed graphically in Figure 1. The black bars represent the confidence interval on these estimates derived from the standard errors found in the source paper. By 2035, the number of misdemeanors is projected to be 960 fewer thanks to full participation in the MPCP. This results in a net societal savings of around $\$ 1.7$ million relative to what would be expected if these students had attended traditional public schools in Milwaukee.

\section{Figure 1: Cumulative Economic Benefit Through Full MPCP Participation: Misdemeanor Reductions}

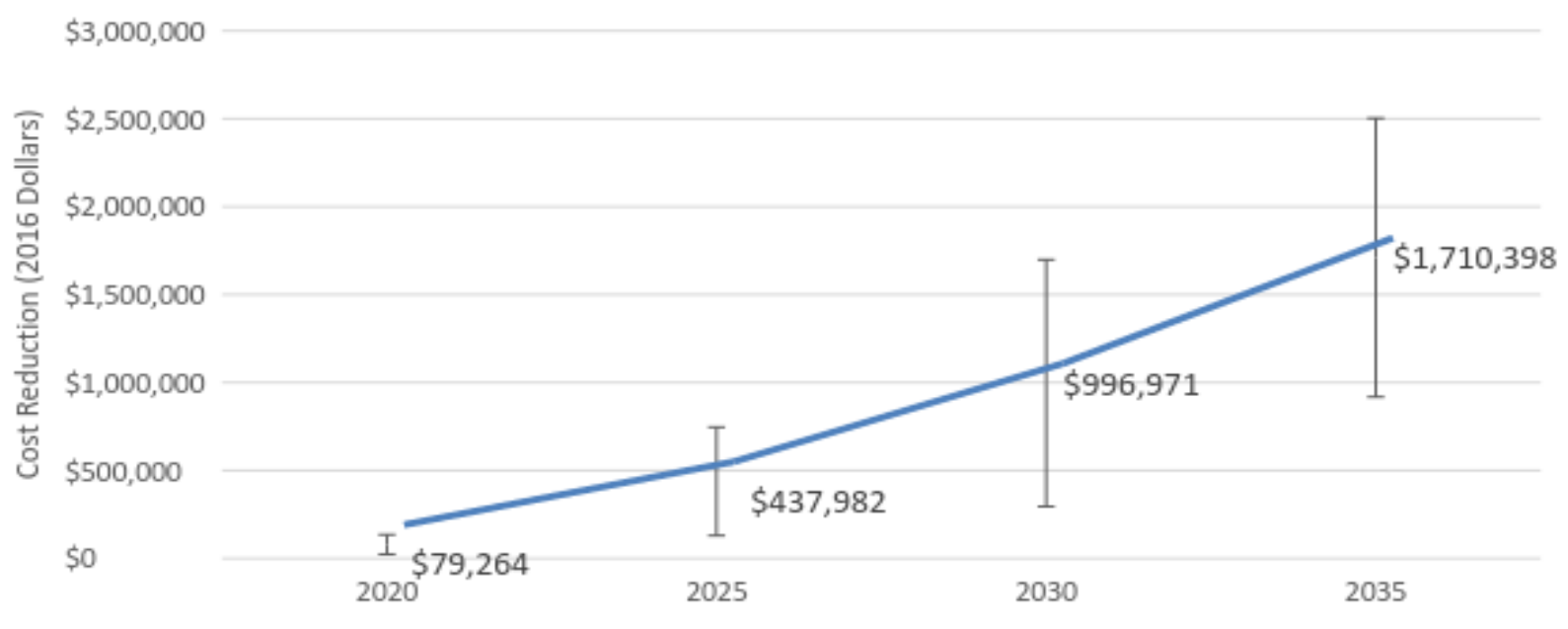


Table 2 presents the results for felony reduction. Over the next twenty years, participation in the MPCP is projected to result in 694 fewer felonies being committed by participants. Although the projected reduction in felonies is smaller than the projected reduction in misdemeanors, these crimes are generally far more costly to society. As such, the economic benefits from reduced felonies far exceed those estimated for misdemeanors. By 2020, reduced felonies are already expected to have a net economic benefit over $\$ 1$ million. Over the following 15 years, or by 2035 , these net economic benefits are projected to be around $\$ 24$ million more than if the students had remained in traditional public schools.

Table 2: Projected Cumulative Economic Benefits of Decreased Felonies

\begin{tabular}{|l|cccc|}
\hline & $2016-2020$ & $2016-2025$ & $2016-2030$ & $2016-2035$ \\
\hline Total Full Dose Students & 934 & 10,304 & 16,522 & 28,537 \\
Reduction in Felonies & 32 & 178 & 404 & 694 \\
Economic Benefits (Millions) & $\$ 1.12$ & $\$ 6.19$ & $\$ 14.08$ & $\$ 24.16$ \\
\hline
\end{tabular}

Note: Numbers represent the mean estimated economic benefit of the MPCP from reduction in felonies from 2016 through 2035.

Figure 2: Cumulative Economic Benefit Through Full MPCP $\$ 35,000,000$ Participation: Felony Reduction

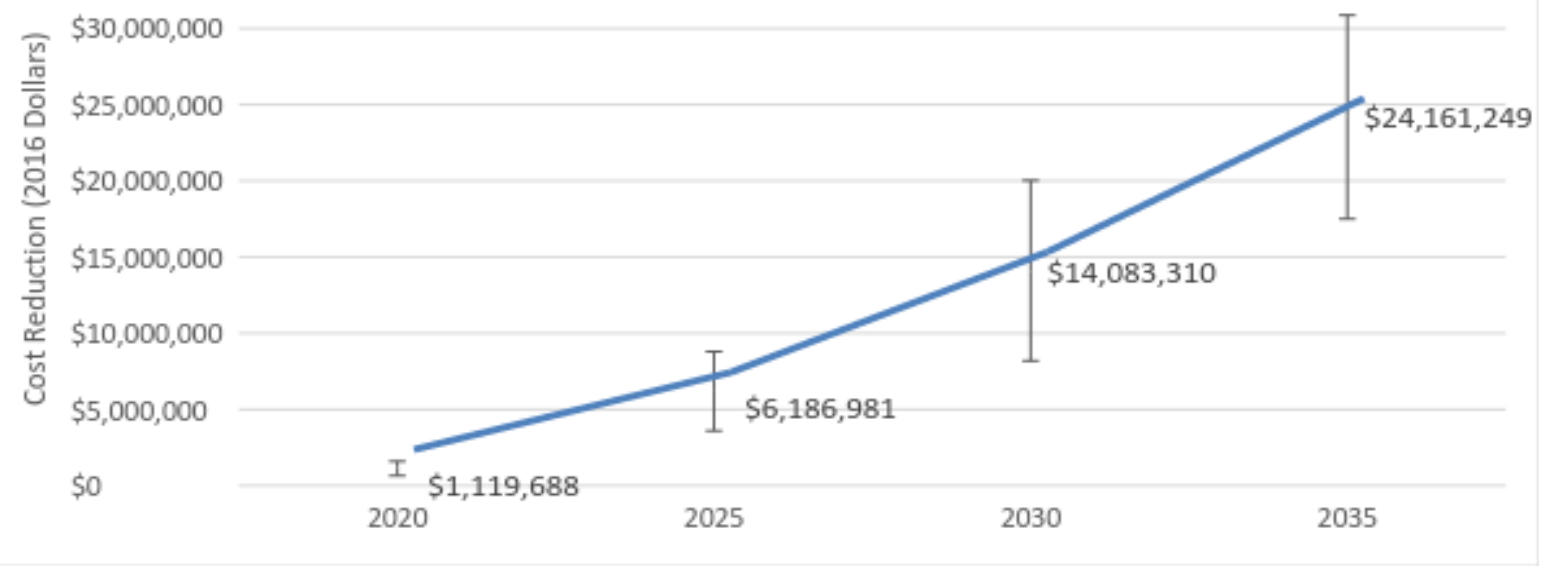




\section{Graduation}

Extrapolating from the estimates of Cowen et al. (2013) and the estimates of the economic benefits of graduation from Levin (2009), we estimate the economic benefits from the increased graduation rates observed in the MPCP. Levin included a cost savings from the reduction in criminality associated with high school graduation in his estimates. To avoid double-counting savings across our graduation and criminality estimates, we leave that component out of our estimates. Table 3 depicts the savings through 2035.

The first row of table 3 represents total number of cohorts who have completed school since the first year under study, 2016. Note that the total completed is significantly higher in this case because the graduation estimates of Cowen et. al. (2013) do not rely on the "full dose" of the program required for the crime study of Wolf and DeAngelis (2016). The second row of the table represents the projected change in the number of graduates relative to what would have happened if those students had remained in traditional public schools. Among students currently enrolled in MPCP, we expect an increase of approximately 1,380 graduates compared to the number of graduates if the students had remained in their assigned public school. According to Levin, graduating from high school increased lifetime economic benefits by approximately $\$ 182,500$ per student. Multiplying these two figures means that the MPCP will earn the state approximately \$29.4 million over the lifetime of currently enrolled students. Assuming continued enrollment growth trends, there are projected to be approximately 1,141 more graduates relative to students who remained in MPS by 2035. These economic savings from these students are projected to be over $\$ 473$ million by 2035 .

These benefits are substantially greater than those found in recent research by Wolf and McShane (2013) on the voucher program in Washington D.C, despite smaller average effects on 
graduation rates than have been found in that program. This may be largely explained by the far smaller number of students who are enrolled in the D.C. program.

Table 3: Projected Cumulative Economic Benefits of Increased Graduation

\begin{tabular}{|l|cccc|}
\hline & $2016-2020$ & $2016-2025$ & $2016-2030$ & $2016-2035$ \\
\hline Total Completed & 9,154 & 23,418 & 41,623 & 64,858 \\
Increase in Graduates & 366 & 937 & 1,665 & 2,594 \\
Economic Benefits (Millions) & $\$ 66.80$ & $\$ 171.00$ & $\$ 303.86$ & $\$ 473.41$ \\
\hline
\end{tabular}

\section{Figure 3: Cumulative Economic Benefit of MPCP: Graduation}

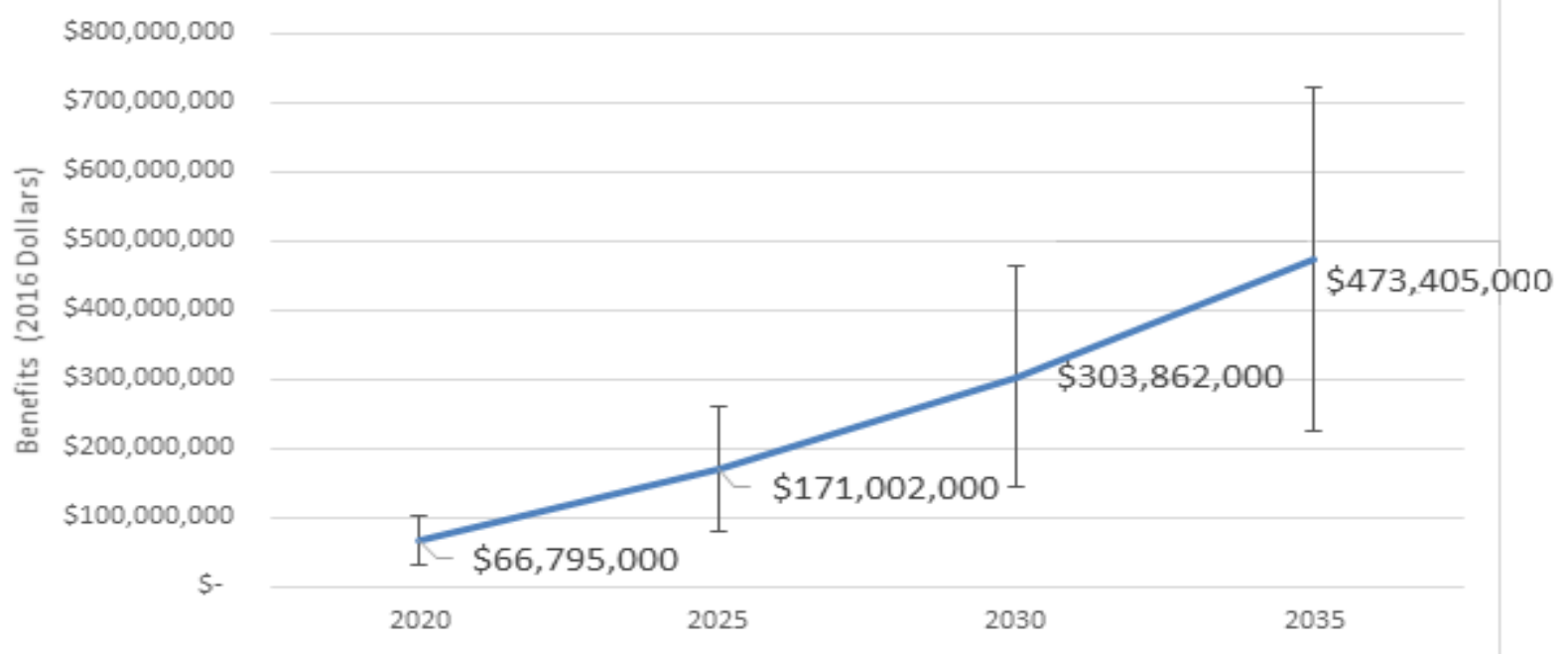

\section{Limitations}

Because we are making projections into the future, there is the potential that the growth rates we assume will be faster or slower. Second, we must rely on national data sets for our estimates of economic benefits because no such data are available for Wisconsin. It is possible that the economic benefits from graduation are higher or lower in Wisconsin than scholars have estimated at the national level. 
Additionally, while the estimates for the economic benefit of each school in our case study is sound, the comparisons with MPS should not be taken with the same level of confidence as those in the rest of the paper. This is because these estimates are based on the average graduation rate in MPS rather than the fine-grained matching data used in the main paper.

\section{Discussion}

This paper represents the most comprehensive estimate of the economic benefits of the MPCP. The program educates children at a significantly lower cost to taxpayers than traditional public schools while delivering economic benefits that measure in the hundreds of millions. A number of policy recommendations stem from this analysis. In this paper, we assume a $5 \%$ growth rate for the MPCP over the next decade. If that growth rate can be accelerated, there is the potential that the economic benefits estimates in this paper could be even greater. Policymakers should work to make it less difficult for existing private schools in the program to expand and for new schools to be created. This includes allowing private school operators to be their own Local Education Agency, streamlining the process for the sale of MPS buildings that have sat vacant for many years, and eliminating the income cap on the program.

Benefits of the MPCP extend beyond traditional measures such as test scores. The reasons behind higher graduation rates and lessened involvement in the criminal justice system are not immediately clear. Such intangibles like a greater ability to instill moral values and the fostering of more positive learning environments likely play a role. However, the end-product of these intangibles is readily measurable. School choice is likely to save Wisconsin hundreds of millions of dollars over and above the difference in the per-student funding that public and choice students receive. 


\section{References}

Anderson, D. Mark. (2014).”'In School and Out of Trouble? The Minimum Dropout Age and Juvenile Crime.” The Review of Economics and Statistics 96: 318-331

Aos, Steve. Polly Phips, Robert Barnoski and Roxanne Lieb. (2001). The Comparative Costs and Benefits of Programs to Reduce Crime. Washington State Institute for Public Policy.

Bifulco, Robert. (2012). “Can Nonexperimental Estimates Replicate Estimates Based on Random Assignment in Evaluations of School Choice? A Within-Study Comparison.” Journal of Policy Analysis and Management 31: 729-751

Cohen MA. (1988). Pain, suffering, and jury awards: a study of the cost of crime to victims. Law Society Review 22: 537-555.

Costrell, Robert M. (2012). The Fiscal Impact of the Milwaukee Parental Choice Program. School Choice Demonstration Project.

Cowen, Joshua, David Fleming, John F. Witte, Patrick Wolf, and Brian Kisida. (2013). School Vouchers and Attainment: Evidence from a State-Mandated Study of Milwaukee's Parental Choice Program. Policy Studies Journal 41: 147-168.

DeAngelis, Corey and Patrick Wolf. (2016). The School Choice Voucher: A 'Get Out of Jail' Card? School Choice Demonstration Project.

Deming, David J. (2011). Better Schools, Less Crime? Quarterly Journal of Economics. Dills, Angela and Rey Hernandez-Julian. (2011). More Choice, Less Crime. Education Finance and Policy 6: 246-266.

Dobbie, W., \& Fryer Jr, R. G. (2015). The Medium-Term Impacts of High-Achieving Charter Schools. Journal of Political Economy, 123(5), 985-1037. 
Levin, Henry. (2009). The Economic Payoff to Investing in Educational Justice. Educational Researcher 38: 5-20.

McCollister, Kathryn E., Michael French and Hai Fang. (2010). The Cost of Crime to Society: New Crime-Specific Estimates for Policy and Program Evaluation. Drug and Alcohol Dependency 108: 98-109

Pawasarat, John and Lois Quinn (2013). Wisconsin's Mass Incarceration of African American Males: Workforce Challenges for 2013. Employment and Training Institute, University of Wisconsin Milwaukee.

Public Policy Forum. 2015. $17^{\text {th }}$ Annual Census of the Milwaukee Parental Choice Program. Spalding, Jeff. (2014). The School Voucher Audit: Do Publically Funded Private School Choice Programs Save Money? The Friedman Foundation for Educational Choice.

Stuart, Elizabeth A., and Donald A. Rubin. (2007). "Best Practices in Quasi-Experimental Design: Matching Methods for Causal Inference." In Best Practices in Quantitative Methods, Jason Osborne Eds.

Waldfogel J, Garfinkel I, Kelly B. (2007). Public Assistance Programs: How Much Could be Saved with Improved Education? In: Belfield C, Levin HM, editors. The Price We Pay. Washington DC: Brookings Institution Press; 2007. pp. 160-176.

Warren, John. (2011). Graduation Rates for Choice and Public School Students in Milwaukee, 2003-2009. School Choice Wisconsin.

Wolf, Patrick and Michael McShane. (2013). Is the Juice Worth the Squeeze? A Cost/Benefit Analysis of the District of Columbia Opportunity Scholarship Program. Education Finance and Policy 8: 74-99. 
Wolf, Patrick, Babette Gutmann, Michael Puma, Brian Kisida, Lou Rizzo, Nada Eissa, Matthew Carr and Marsha Silverberg. (2010). Evaluation of the DC Opportunity Scholarship Program: Final Report. National Center for Education Evaluation and Regional Assistance. 